\section{Basal cell carcinoma trends in Thailand: A 10-year retrospec- tive study of demographic, clinical and histopathological features}

\author{
Anakaporn Tiyawatanaroj, Poonnawis \\ Sudtikoonaseth, Onjuta Chayangsu \\ Institute of Dermatology, Bangkok, \\ Thailand
}

\begin{abstract}
Basal cell carcinoma (BCC) is the most common skin cancer with globally increasing incidence. To date, the information regarding BCC in Thailand is limited. Our aim was to evaluate the demographic, clinical, histopathological trends of BCC and other contributing factors. We retrospectively reviewed the demographic, clinical and histological data of all BCC outpatients from January 2009 to December 2018. From 278 BCC patients recruited to this study, most of them $(71.6 \%)$ were older than 60 years old. The most common histological subtype was nodular BCC (63.3\%). A statistically significant association was observed between histological variant and location of the tumor; $\mathrm{H}$ and $\mathrm{M}$ area were associated with nodular BCC; L area was related to superficial subtype $(\mathrm{P}<0.001)$. Misdiagnosis of BCC was observed in 53 cases, mostly as melanocytic nevus $(30.2 \%)$, and about quarter $(26.4 \%)$ was made by board-certified dermatologists. Nodular BCC is significantly associated with $\mathrm{H}$ and $\mathrm{M}$ area, while superficial subtype is related to L location. Quarter of the patients already have large tumors at their first presentation. Misdiagnosis of BCC is not uncommon.
\end{abstract}

\section{Introduction}

Non-melanoma skin cancer (NMSC), comprising of basal cell carcinoma (BCC) and squamous cell carcinoma (SCC), is the most commonly occurring malignant tumor in white populations. BCC accounts for most $(80 \%)$ of it. ${ }^{1}$ Despite the difficulties in capturing and registering data leading to underreporting of $\mathrm{BCC}$, an upward trend in overall incidence has been noted. ${ }^{1,2}$ The incidence rate of $\mathrm{BCC}$ in United States(US) arose approximately $18 \%$ during 15-year period up to 535 cases per 100,000 personyears in 2012. ${ }^{1}$ This may be linked to the rising of aging population, sun-seeking behavior and recent advance in diagnostic technology. ${ }^{1,2}$ Although metastasis and mortality from $\mathrm{BCC}$ is rare, it can be locally destructive causing morbidity and significant burden in healthcare system. ${ }^{3-5}$

For Asian patients, BCC lesions frequently develop on sun-exposed area of head and neck region like in Caucasians. ${ }^{6}$ However, female predominance and high prevalence of pigmented variant, described as black pearly appearance, are notably observed in Asians. ${ }^{6,7}$

In Thailand, the age-specific incidence rate of skin cancer is 3.6 and 3.8 per 100,000 person-years for male and female respectively during the year 2013-2015. ${ }^{8}$ In spite of its small incidence compared with those western countries, skin cancer is not uncommon since it is one of the top fifteen leading site of new cancer patients in Thailand. $^{9}$ Moreover, the correlation between anatomical distribution and particular histological subtypes are documented in previous study from Thailand, as superficial $\mathrm{BCC}$ is predominantly occurred on the trunk, while other subtypes are more common on the head and neck. ${ }^{10}$ So far, the data regarding $\mathrm{BCC}$ in Thailand are still restricted, as long as some are in Thai language and some are unsearchable via major online medical databases and most of which are not up to date.

The aim of the present study was to analyze the epidemiologic, clinical, and histological characteristics of BCC in Thailand for 10 years and other associating variables.

\section{Materials and methods}

This study was approved by the Ethics Committee of the Institute of Dermatology, Bangkok, Thailand (IRB/IEB 022/2562) and was performed in accordance with the World Medical Association's Helsinki Declaration and its amendment.

A single-center, 10-year retrospective descriptive study was performed by medical records review of outpatients presented at Institute of Dermatology, Bangkok, Thailand from January 2009 to December 2018. There were 901 new cases that were diagnosed as primary $\mathrm{BCC}$ during the period. After excluding the tumors diagnosed without pathology reports and without or unclassified histological subtypes, 278 eligible cases were recruited to the study. Patients' demographic data, the duration of tumor's presence, past medical history, cutaneous findings, provisional clinical diagnosis, histological subtypes, treatment regimen and the result were collected.

According to the National Comprehensive Cancer Network (NCCN)
Correspondence: Onjuta Chayangsu, Institute of Dermatology 420/7 Ratchawithi Rd, Thung Phata Thai, Ratchatewi, Bangkok, 10400 Thailand. E-mail: onjuta@gmail.com

Key words: Basal cell carcinoma, skin cancer, non-melanoma skin cancer, histopathology, demography, epidemiology

Acknowledgment: The authors are grateful to Assoc. Prof. Dr. Jaranit Kaewkungwal from Faculty of Tropical Medicine, Mahidol University for his statistical advice.

Contributions: AT contributes to the acquisition, analysis, interpretation of the data, drafting the work, final approval of the version to be published and agreement to be accountable for all aspects of the work. PS contributes to the conception and design of the work, revising the manuscript critically for important intellectual content, final approval of the version to be published and agreement to be accountable for all aspects of the work. OC contributes to the conception or design of the work, drafting the work, revising the manuscript critically for important intellectual content, final approval of the version to be published and agreement to be accountable for all aspects of the work.

Conflict of interest: The authors declared no conflict of interest.

Funding: The authors declared no funding for the study.

Conference presentation: The authors presented this research in the 45th Annual Meeting of Dermatological Society of Thailand (DST), Bangkok, Thailand in February 2020.

Ethics approval: The study was approved by the Ethics Committee of the Institute of Dermatology, Bangkok, Thailand (IRB/IEB $022 / 2562$ ) and was performed in accordance with the World Medical Association's Helsinki Declaration and its amendment.

Please cite this article as: Tiyawatanaroj A, Sudtikoonaseth P, Chayangsu O. Basal cell carcinoma trends in Thailand: A 10-year retrospective study of demographic, clinical and histopathological features. Dermatol Rep 2022;14:9413.

Received for publication: 1 November 2021. Accepted for publication: 27 December 2021

This work is licensed under a Creative Commons Attribution-NonCommercial 4.0 International License (CC BY-NC 4.0).

( $C$ Copyright: the Author(s), 2022

Licensee PAGEPress, Italy

Dermatology Reports 2022; 14:9413

doi:10.4081/dr.2022.9413 
guideline, the anatomical location of BCC in the study was classified into 3 groups including $\mathrm{H}$ (central face, eyelids, eyebrows, periorbital, nose, lips, chin, mandible, pre- and postauricular, ear, temple, genitalia, hands and feet), M (forehead, cheeks, scalp, neck and pretibia) and $\mathrm{L}$ area (trunk and extremities, excluding hands, feet, nails, pretibial and ankles). ${ }^{11}$

Descriptive statistics were used to describe the demographic, clinical and histopathological data. The percentage distribution of BCC cases was calculated according to the variables. The associations of the variables were analyzed by the Pearson $\chi^{2}$ test. Multiple logistic regression analysis was performed to test the association among multiple variables and histologic subtype simultaneously. All statistical analyses were done using SPSS Statistics 23.0 (IBM corporation, Armonk, NY, USA). The P-value $<0.05$ was considered statistically significant.

\section{Results}

From a total of 901 new BCC cases diagnosed between January 2009 and December 2018, 278 cases were enrolled to the study. The trend of number of cases each consecutive year was demonstrated in Figure 1. The male to female ratio was 0.73 (161 females and 117 males). The patients were classified into three age groups: $<40$, $40-60$ and $>60$ years of age. Most of them $(71.6 \%)$ were more than 60 years old, as shown in Figure 2. Nearly all of the patients $(88.8 \%)$ were Thais and $41.0 \%$ of all were living in Bangkok.

About half $(50.6 \%)$ of the patients had the tumor for less than 2 years, whereas $16.9 \%$ of them had the lesion for longer than 5 years before seeking medical attention $($ mean $\pm \mathrm{SD}=3.10 \pm 4.53$ years $)$. Concerning anatomical location, 146

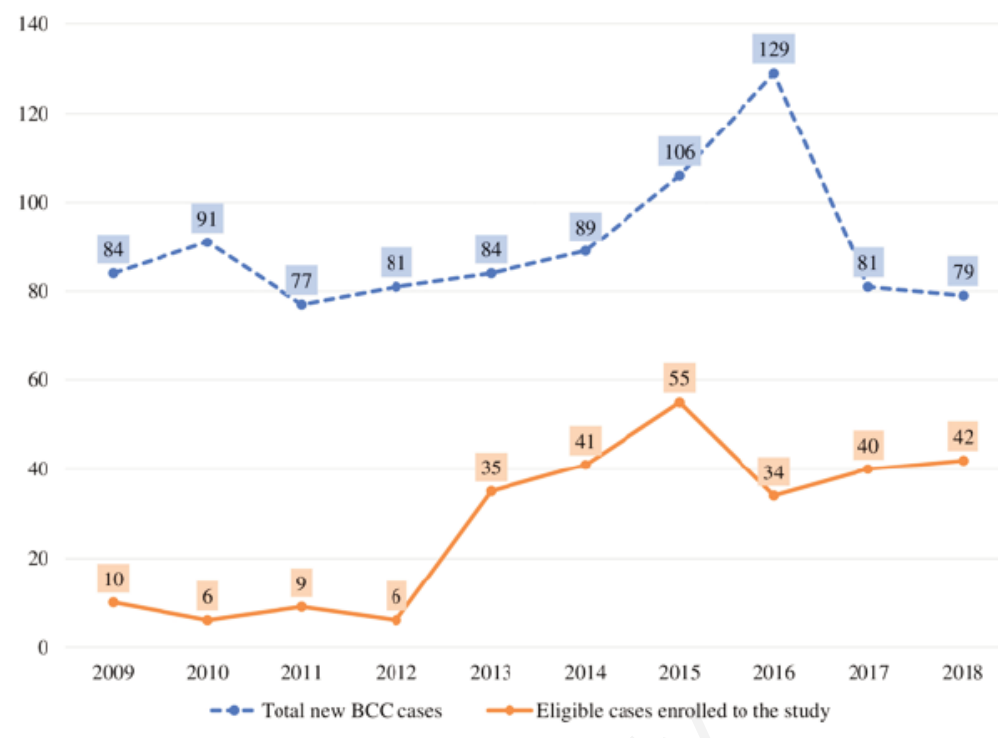

Figure 1. The annual number of total new basal cell carcinoma cases and eligible cases enrolled to the study during 10 -year study period.

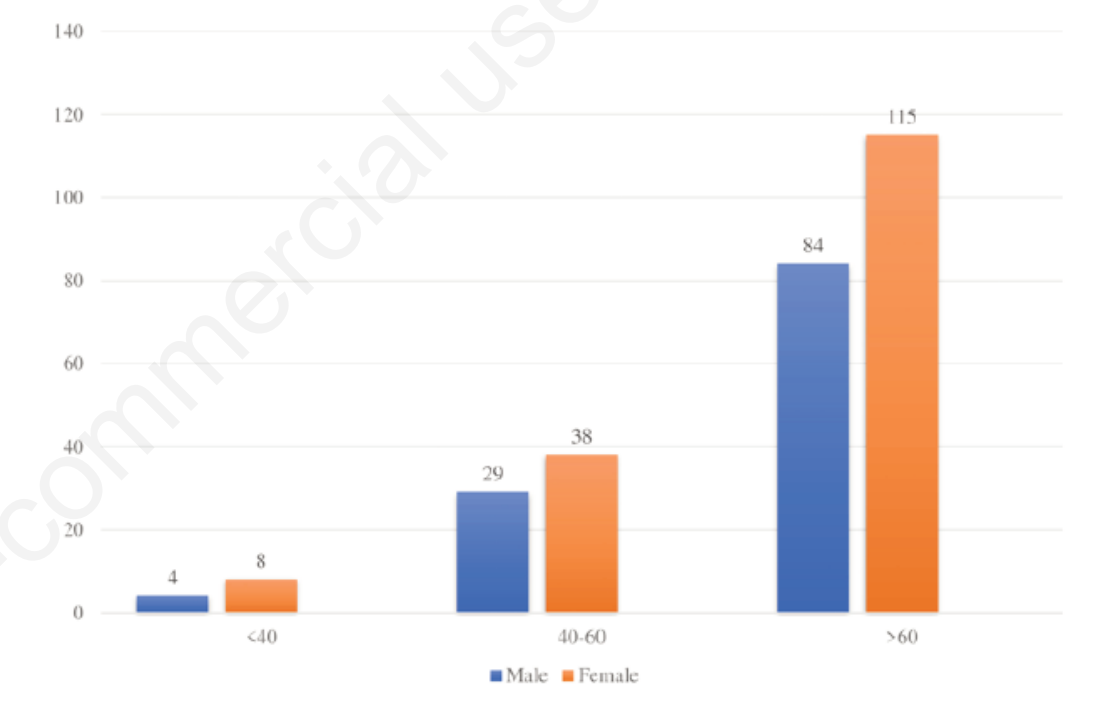

Figure 2. Age distribution of basal cell carcinoma patients $(n=278)$.

Table 1. Multiple logistic regression analysis of patients' sex, age group, tumor's anatomical location related to basal cell carcinoma histological subtype.

\begin{tabular}{|c|c|c|c|}
\hline \multirow[t]{2}{*}{ Variables } & \multicolumn{3}{|c|}{ Histological subtype of basal cell carcinoma - OR ( $95 \%$ CI) } \\
\hline & Nodular subtype & Superficial subtype & Others \\
\hline \multicolumn{4}{|l|}{ Sex } \\
\hline Male & $0.94(0.56-1.55)$ & $1.53(0.73-3.21)$ & $0.84(0.48-1.46)$ \\
\hline Female & $1.06(0.65-1.74)$ & $0.65(0.31-1.37)$ & $1.20(0.69-2.10)$ \\
\hline \multicolumn{4}{|c|}{ Age group (years) } \\
\hline$>40$ & 1 & 1 & 1 \\
\hline $40-60$ & $1.06(0.30-3.68)$ & $1.50(0.17-13.15)$ & $0.80(0.21-2.94)$ \\
\hline$>60$ & $1.31(0.40-4.30)$ & $1.73(0.21-13.92)$ & $0.55(0.16-1.92)$ \\
\hline \multicolumn{4}{|c|}{ Anatomical location of tumor } \\
\hline L area & 1 & 1 & 1 \\
\hline M area & $7.30(3.03-17.64)^{*}$ & $0.05(0.02-0.15)^{*}$ & $1.27(0.47-3.48)$ \\
\hline $\mathrm{H}$ area & $5.03(2.31-12.29)^{*}$ & $0.06(0.03-0.16)^{*}$ & $1.70(0.66-4.42)$ \\
\hline
\end{tabular}

OR: odd ratio; CI: confidence interval; ${ }^{*} \mathrm{P}<0.001$. 
(52.5\%), 98 (35.3\%) and 34 (12.2\%) BCCs were located on $\mathrm{H}, \mathrm{M}$ and $\mathrm{L}$ area, respectively. The most common site of distribution was the nose ( 80 cases, $28.8 \%$ ), followed by cheek (68 cases, $24.5 \%$ ), periorbital area (27 cases, 9.7\%), trunk ( 20 cases, $7.2 \%$ ) and forehead (19 cases, 6.8\%). From all, $172(61.9 \%)$ were pigmented lesions, which totally occurring in Asians, and 121 (43.5\%) BCCs were ulcerated. Most of the BCC tumors $(60.2 \%)$ were less than $10 \mathrm{~mm}$ in size, but $14.3 \%$ of them were bigger than $20 \mathrm{~mm}$. The initial clinical diagnosis was made correctly before performing the skin biopsy in 225 cases $(80.9 \%)$. Whereas the rest $(19.1 \%)$, presented in Figure 3, were misdiagnosed as melanocytic nevus, seborrheic keratosis, Bowen's disease, actinic keratosis, squamous cell carcinoma, melanoma and others. Regarding 53 misdiagnoses, 14 cases $(26.4 \%)$ were evaluated by board-certified dermatologists and 39 cases $(73.6 \%)$ were assessed by the trainees: dermatology residents or postgraduate diploma students.

The distribution of histological subtypes showed the predominance of the nodular BCC (176 cases, 63.3\%), followed by mixed (48 cases, $17.3 \%$ ) and superficial subtype (36 cases, 12.9\%). According to Table 1, a significant association between anatomical distribution and histological subtype was revealed in the study. $\mathrm{H}$ area $(\mathrm{OR}=5.03$, 95\% CI 2.31-12.29, P-value $<0.001)$ and $\mathrm{M}$ area $(\mathrm{OR}=7.30,95 \% \mathrm{CI}$ 3.03-17.64, $\mathrm{P}$-value $<0.001)$ were related to nodular BCC, while L area was linked to superficial BCC. Association between pigmented lesion and nodular type was found $(\mathrm{OR}=1.99$, 95\% CI 1.20-3.31, P-value $<0.001)$. There was no statistically significant association between sex, age group and the histological subtype $(\mathrm{P}>0.05)$.

Most of the patients $(84.5 \%)$ were surgically treated, though 18 patients $(6.5 \%)$ got non-surgical modalities (cryosurgery, electrodesiccation and curettage, photodynamic therapy and/or topical medications). The majority of the tumors $(87.7 \%)$ were completely cured, 2 patients $(0.7 \%)$ who obtained non-surgical treatment had tumor recurrence and the rest were referred to other hospitals. No metastasis was seen.

\section{Discussion}

Based on formerly published data, the incidence of NMSC in Asians is low when compared with populations in Australia, US and western countries. However, there is approximately $10 \%$ per year rise in the incidence of BCC worldwide. ${ }^{1,2,12,13}$ This ascending trend was also noticed in our study until 2016, since after that year the hospital building was under renovation which could affect the patients' accessibility. Most of the patients in the present study were older than 60 years old. Head and neck area was the most common location of BCC tumors. In addition, relatively female predominance was observed in the study. These findings were similar to the prior research reporting majority of older age group and head and neck region in overall BCC patients. ${ }^{1,6}$ Though, female gender predilection is noted only in Hispanic and Asians. ${ }^{6}$

BCC typically runs a gradually progressive course; some tumors may grow at a very slow rate and behave like benign conditions. ${ }^{14}$ This could be a possible explanation that a quarter of the patients in current study had the tumors for longer than 5 years before they started seeking medical care. Also, quarter of them already had very large tumors (greater than 20-mm in size) at their first presentation. Patient's education about skin cancer self-examination may help to improve this problem in Thailand.

Pigmented BCC was observed in $61.9 \%$ of the patients in this study and was significantly correlated with nodular histological subtype. The findings were consistent with previous observations accounting that pigmented BCC has obviously higher prevalence in Asians, some describe the clinical appearance of brown or black pigmentation, especially at the border of the lesions. ${ }^{6,7,15}$ However pigmented BCC is a clinical and histological term, it could be microscopically superficial or nodular histological subtypes containing melanin. ${ }^{14}$ According to their dark colors, pigmented BCC had sometimes been misdiagnosed as other pigmented skin conditions. Therefore, it is very important for clinicians to consider BCC as one of the differential diagnosis in Asian patients. ${ }^{6}$ In the present study, we found misdiagnosis of BCC in $19.1 \%$ of all cases, surprisingly about one-fourth (26.4\%) were made by board-certified dermatologists. The lesions were mostly misdiagnosed as benign and premalignant cutaneous tumors including melanocytic nevus, seborrheic keratosis, Bowen's disease and actinic keratosis. In order to improve this issue, the dermoscope may play an essential role. As some clues from dermoscope such as leaflike structures, blue ovoid nest, arborizing vessels and ulceration can enhance the sensitivity and specificity for BCC detection. ${ }^{16}$ From current study, nodular BCC was the most common histological subtype. This finding was in concordance with previous studies from many countries. .,14,17 $^{-1}$ Besides, previous researches identify a significant association between the histopathologic subtypes and anatomical location, with nodular BCC being more common on chronically sun-exposed area (e.g. head and neck), while superficial BCCs were more likely to be located on trunk and extremi-

Figure 3. Provisional diagnosis other than basal cell carcinoma $(n=53)$. 
ties. ${ }^{10,14,17}$ We also established the comparable result that $\mathrm{H}$ and $\mathrm{M}$ area were associated with nodular subtype, whereas L area was related to superficial BCC. ${ }^{14}$

Considering younger age group, superficial BCC is found to be the most common BCC subtype. ${ }^{14,17}$ Furthermore, a study from Canada reports that superficial BCC is more common in women. ${ }^{18}$ However, there were no significant association between age group, sex and histological subtype in our study. There were some limitations in the current study. First, this was an academic setting, single center study which may not be the representative of whole Thai populations. Second, the pathology reports were conducted by different pathologists from both inside and outside the institute, which may affect the histological classification of the tumors. Third, because of the retrospective nature, patient modifiers such as some environmental and behavioral factors were not recorded, thus their association with the tumors could not be established. Further large multicenter study or nationwide collaboration would be appreciated.

\section{Conclusions}

In conclusion, $\mathrm{BCC}$ is prominently occurred in elderly people. Pigmented BCC is predominated in Asians. Nodular BCC is the most common histological subtype. There is a significant association between histological subtype and anatomical location, as nodular subtype is associated with $\mathrm{H}$ and $\mathrm{M}$ area, while superficial BCC was linked to L location. Quarter of the patients have the long history of large tumors before seeking medical attention. Patient's education about skin cancer may help to improve this situation. The clinical misdiagnosis of $\mathrm{BCC}$ was not unusual; therefore, the clinicians should consider BCC as one of the differential diagnosis of pigmented skin conditions in Asian populations.

\section{References}

1. Asgari MM, Moffet HH, Ray GT, et al. Trends in basal cell carcinoma incidence and identification of high-risk subgroups, 1998-2012. JAMA Dermatol 2015;151:976-81.

2. Lomas A, Leonardi-Bee J, Bath-Hextall F. A systematic review of worldwide incidence of nonmelanoma skin cancer. Br J Dematol 2012;166:1069-80.

3. Leiter U, Keim U, Garbe C. Epidemiology of skin cancer: Update 2019. Adv Exp Med Biol 2020;1268: 123-39.

4. Eisemann N, Waldmann A, Geller AC, et al. Non-melanoma skin cancer incidence and impact of skin cancer screening on incidence. J Invest Dermatol 2014;134:43-50.

5. Ciążyńska M, Narbutt J, Woźniacka A, Lesiak A. Trends in basal cell carcinoma incidence rates: a 16-year retrospective study of a population in central Poland. Adv Dermatol Allergol 2018;35:47-52.

6. Loh TY, Ortiz A, Goldenberg A, Brian Jiang SI. Prevalence and clinical characteristics of nonmelanoma skin cancers among Hispanic and Asian patients compared with white patients in the United States: A 5-year, single-institution retrospective review. Dermatol Surg 2016;42:639-45.

7. Kikuchi A, Shimizu H, Nishikawa T. Clinical and histopathological characteristics of basal cell carcinoma in Japanese patients. Arch Dermatol 1996;132:320-4.

8. Imsamran W, Pattatang A, Supaattagorn $\mathrm{P}$, et al., editors. Cancer in Thailand Vol.IX, 2013-2015. Bangkok: New Thammada Press; 2018.

9. National Cancer Institute, Department of Medical Services, Ministry of Public Health, Thailand. Hospital-based cancer registry annual report 2014. Bangkok: Pornsup Printing; 2016.
10. Puavilai S, Sirapan S. Correlation of histological subtypes of basal cell carcinoma with age, sex and distribution of skin lesions: a five-year study at Ramathibodi Hospital. J Med Assoc Thai 2002;85:560-4.

11. Bichakjian CK, Olencki T, Aasi SZ, et al. Basal Cell Skin Cancer, Version 1.2016, NCCN Clinical Practice Guidelines in Oncology. J Natl Compr Canc Netw 2016;14:574-97.

12. Sng J, Koh D, Siong WC, Choo TB. Skin cancer trends among Asians living in Singapore from 1968 to 2006. J Am Acad Drmatol 2009;61:426-32.

13. Perera E, Gnaneswaran N, Staines C, et al. Incidence and prevalence of nonmelanoma skin cancer in Australia: A systematic review. Australas J Dermatol 2015;56:258-67.

14. Cameron MC, Lee E, Hibler BP, et al. Basal cell carcinoma epidemiology; pathophysiology; clinical and histological subtypes; and disease associations. J Am Acad Dermatol 2019;80:303-17.

15. Cheng SY, Luk NM, Chong LY. Special features of non-melanoma skin cancer in Hong Kong Chinese patients: 10-year retrospective study. Hong Kong Med J 2001;7:22-28.

16. Yélamos O, Braun RP, Liopyris K, et al. Usefulness of dermoscopy to improve the clinical and histopathological diagnosis of skin cancers. J Am Acad Dermatol 2019;80:365-77.

17. Scrivener Y, Grosshans E, Cribier B. Variations of basal cell carcinomas according to gender, age, location and histopathological subtype. $\mathrm{Br} \mathrm{J}$ Dermatol 2002;147:41-7.

18. Rivers JK, Mistry BD, Hung T, et al. A 13-year retrospective study of basal cell carcinoma in a Canadian practice: a comparison between anatomical location and histopathological subtypes. J Cutan Med Surg 2016;20:233-240. 